\title{
Trust in healthcare and science
}

Henk ten Have ${ }^{1} \cdot$ Bert Gordijn ${ }^{2}$

Published online: 9 May 2018

(c) Springer Science+Business Media B.V., part of Springer Nature 2018
Trust is generally regarded as a basic concept in healthcare and science. Without trust, physicians will not be able to provide for their patients. Scientists will no longer be supported when they have lost the trust of the general public. If scientific publications are no longer reliable, for example because they have been ghost-written or published in predatory journals, the readership will lose confidence in the data produced by researchers. The journal issue at hand includes several contributions related to trust. Research projects, especially large-scale initiatives at national and regional levels, will only be effective if they can build on public trust. Such trust will be obtained if emphasis is put on ethics and ethical governance. Samuel and Farsidis (2018) discuss the 'genomic dream' in the United Kingdom of integrating genomics in all aspects of the National Health Service (NHS). This dream can only be realized if the ethical aspects are seriously taken into account. The promoters of the project strongly displayed ethical concerns on the website and in public events. An Ethics Advisory Board Committee was established, and a bioethicist was invited to sit on the Board of the project. This emphasis on ethics was intended to assure the public that ethics was taken into account in decision-making procedures and governance, and that therefore the project could be trusted. Samuel and Farsidis ask the critical question whether this focus on ethics is more strategic than substantial. Being perceived as ethical is not the same as being ethical. Interviewing participants in the project showed that they do not want to appear ethical but also want to act ethically. They also clarified a disconnect between the public presentation of the project and the actual discussions with patients. The project website, for example, gave prominence to ethical concerns of privacy and commercial interaction, while from the patient perspective concerns with health benefits were more prominent. The
Henk ten Have
tenhaveh@duq.edu
Pittsburgh, PA, USA
2 Dublin, Ireland

implication is that public trust apparently has two components. One is the need of projects to be viewed as ethical. This is the external guarantee for trust. It emphasizes procedures and mechanism such as the existence of an ethics committee, and the attention paid to well-known concerns of privacy and conflict of interest. The other component, however, is an internal one, demonstrating that in practice there will be ongoing discussions between people involved in the project; these discussions will be iterative since practices are uncertain and messy. Samuel and Farsidis rightly point out that there are certain limits to this internal ethics. The ethical presuppositions, the moral worth and scientific validity of the project itself cannot be questioned. When the project has been launched, certain ethical presuppositions need to be taken for granted. This is of course an important lesson for the issue of trust. If the importance and the appropriateness of a project cannot be questioned, the public is asked to trust the prior decision-making process. How have decisions been made to incorporate genomics into the NHS? Such decisions are often political and not necessarily open to ethical scrutiny.

The lay perspective on trust is explored in the contribution of Sheikh and Hoeyer (2018). The authors make clear that trust is not a uniform concept. For research participants at least in Pakistan and Denmark trust is not directly invested in individual researchers but depends on divinity or the system. For research subjects in Pakistan, often in conditions of poverty and lack of access to healthcare, trust also depends on expectations such as hope for cures and opportunities for better care. In Denmark hope for future generations is more important that the expectation to improve the current situation but what most concerns Danish participants are risks such as disclosure of sensitive information. The fact that the meaning of trust is different in cultural settings (in this case Pakistan and Denmark) illustrate that procedural mechanisms such as transparency and ethics committees are not sufficient to create trust, and to convince people to participate in research. Trust is created within the process of participating itself. 
Trust plays an important role in contemporary research ethics which is nowadays focusing on the notion of scientific integrity. Patrão Neves (2018) argues that the notion of scientific integrity refers to honesty, commitment to truth, independence, freedom of inquiry, and impartiality. These are the foundations for the trust of society in science. Integrity and trust are not only important for personal action but also for professional activity. Trust is a motivating force for the World Medical Association. Already in 1948, the WMA adopted the Declaration of Geneva, followed in 1949 by the International Code of Medical Ethics. However, trust is not mentioned in either document. Nevertheless, Rheinberg et al. (2018) argue that public trust in the profession has been and still is an important concern. They contend that the Declaration of Geneva, and especially its updated version of 2016 is intended as a modernized version of the Hippocratic Oath. It identifies the common moral basis for medical professionals, regardless where they practice. The fact that the basic principles are uniform is exactly why patients can trust health professionals; they can be confident that they receive the same treatment based on the same principles. Rheinberg at al. (2018) therefore recommend there be one single binding oath for the entire medical profession in a globalized world. This is a sympathetic point of view but the problem with trust remains. It is built not only on what we say but on what we do. In ethics, words, statements and declarations are important but perhaps even more significant are acts and deeds.

\section{References}

do Ceu Patrão Neves, M. 2018. On scientific integrity: Conceptual clarification. Medicine, Health Care and Philosophy 21 (2), this issue.

Rheinberg, Z., R. Parsa-Parsi, O. Kloiber, and U. Wiesing. 2018. Medical oath: Use and relevance of the Declaration of Geneva. A survey of member organizations of the World Medical Association (WMA). Medicine, Health Care and Philosophy 21 (2), this issue.

Samuel, G. B., and B. Farsidis. 2018. Public trust and 'ethics review' as a commodity: The case of Genomics England Limited and the UK's 100,000 genomes project. Medicine, Health Care and Philosophy 21 (2), this issue.

Sheikh, Z., and K. Hoeyer. 2018. "That is why I have trust": Unpacking what 'trust' means to participants in international genetic research in Pakistan and Denmark. Medicine, Health Care and Philosophy 21 (2), this issue. 